\title{
Hubungan Indeks Massa Tubuh terhadap Dysmenorrhea pada Mahasiswi Fakultas Kedokteran Universitas Kristen Krida Wacana Angkatan 2015
}

\author{
Budiman Hartono ${ }^{1}$, Fallentino Christman Leuhery ${ }^{2}$ \\ ${ }^{1}$ Departemen Biologi, Fakultas Kedokteran dan Ilmu Kesehatan, Universitas Kristen Krida \\ Wacana, Jakarta, Indonesia. \\ ${ }^{2}$ Fakultas Kedokteran dan Ilmu Kesehatan, Universitas Kristen Krida Wacana, Jakarta, \\ Indonesia. \\ Alamat Korespondensi : E-mail: budimanhrtn@yahoo.com
}

\begin{abstract}
Abstrak
Kelebihan berat badan menjadi masalah yang meningkat di Indonesia Kelebihan berat badan dikatakan sebagai faktor risiko bagi perempuan yang menstruasi menderita dysmenorrhea.

Penelitian ini bertujuan untuk menganalisis ada tidaknya hubungan antara indeks massa tubuh (IMT) terhadap dysmenorrhea pada mahasiswi Fakultas Kedokteran Universitas Krida Wacana (UKRIDA) angkatan 2015. Penelitian ini menggunakan desain korelasi analitik potong lintang. Penelitian ini dilakukan di UKRIDA dari bulan Juni hingga Desember 2018. Subjek penelitian ini adalah mahasiswi aktif Fakultas Kedokteran UKRIDA angkatan 2015 dengan cara menyebarkan kuisoner, microtoise sebagai alat ukur tinggi badan, dan timbangan injak sebagai alat ukur berat badan. Hasil penelitian menunjukkan bahwa rerata umur mahasiswi angkatan 2015 di Fakultas Kedokteran UKRIDA adalah 21 tahun. Indeks massa tubuh normal sebanyak 51 responden $(48,2 \%)$. Derajat nyeri (dysmenorrhea) responden mengeluh nyeri sebanyak 63 responden $(59,4 \%)$ dan didapatkan hubungan yang bermakna antara indeks massa tubuh dengan dysmenorrhea pada mahasisiwi Fakultas Kedokteran UKRIDA angkatan 2015.
\end{abstract}

Kata kunci: dysmenorrhea, indeks massa tubuh, mahasiswi

\section{The Relationship between Body Mass Index with the Incidence of Dysmenorrhea in Students of Faculty of Medicine Krida Wacana Christian University Batch 2015}

\begin{abstract}
Overweight is a problem that is increasingOverweight is a risk factor for dysmenorrhea. The present study aimed to analyse the relationship between body mass index with dysmenorrhea of female students from batch 2015 in UKRIDA Medical Faculty. This is a cross sectional analytical correlation. Data were collected from June until December 2018 using questionnaire, microtaise to measure height, and scales to measure body weight.

The average age of female students were 21 years old. Fifty-one students had normal body weight (48,2\%). Of all respondents, 63 students $(59,4 \%)$ reported pain (dysmenorrhea). The study found relationship between body mass index and dysmenorrhea among the students.
\end{abstract}

Keywords: dysmenorrhea, body mass index, students

How to cite this article :

Hartono, B dan Leuhery, FC. Hubungan Indeks Massa Tubuh terhadap Dysmenorrhea pada Mahasiswi Fakultas Kedokteran Universitas Kristen Krida Wacana Angkatan 2015. Jkdoktmeditek. 2020;26(1): 17-22. https://ejournal.ukrida.ac.id/ojs/index.php/Meditek/article/view/1797. DOI: https://doi.org/10.36452/jkdoktmeditek.v26i1.1797. 


\section{Pendahuluan}

Kelebihan berat badan tidak hanya ditemukan pada orang dewasa tua, tetapi banyak ditemukan pada usia remaja hingga dewasa muda. ${ }^{1}$ Pada negara berkembang kelebihan berat badan menjadi masalah yang sering ditemukan. Faktor-faktor genetik, hormonal, perilaku (gaya hidup), psikososial, dan lingkungan dapat mempengaruhi terjadinya gangguan pada keseimbangan energi tubuh yang dapat menimbulkan kelebihan berat badan. $^{2}$

Berdasarkan hasil Riset Kesehatan Dasar (RISKESDAS) yang dilakukan pada tahun 2018 di Indonesia didapatkan data overweight pada dewasa usia $>18$ tahun terjadi peningkatan dari 11,5\% pada tahun 2013 menjadi 13,6\% pada tahun 2018 dan data obesitas pada dewasa usia $>18$ tahun terjadi peningkatan dari $14,8 \%$ tahun 2013 menjadi $21,8 \%$ pada tahun 2018 . Prevalensi obesitas di Provinsi Daerah Khusus Ibukota (DKI) Jakarta pada usia >18 tahun menduduki peringkat ke dua di Indonesia setelah Sulawesi Utara dengan prevalensi sebesar 29,8\%. Prevalensi Indeks Massa Tubuh (IMT) $>27 \mathrm{~kg} / \mathrm{m}^{2}$ penduduk dewasa muda di Indonesia (umur 18 tahun ke atas) menurut RISKESDAS tahun 2007 menunjukkan sebesar $12,47 \%$. Prevalensi IMT $>25 \mathrm{~kg} / \mathrm{m}^{2}$ penduduk laki-laki dewasa (>18 tahun) pada tahun 2013 sebesar $19,7 \%$, lebih tinggi daripada tahun 2007 (13,9\%) dan tahun 2010 (7,8\%). Akan tetapi, prevalensi IMT $>25 \mathrm{~kg} / \mathrm{m}^{2}$ perempuan dewasa ( $>18$ tahun) pada tahun 2013 sebesar $32,9 \%$, naik $18,1 \%$ dari tahun 2007 (13,9\%) dan peningkatan $17,5 \%$ dari tahun 2010 $(15,5 \%)$. Berdasarkan hasil penelitian yang dilakukan oleh RISKESDAS menunjukkan terjadi peningkatan angka berat badan lebih dan obesitas di Indonesia dan perempuan mempunyai angka kejadian yang lebih tinggi di bandingkan laki-laki. ${ }^{3}$

Istilah overweight adalah kelebihan berat badan atau berat badan yang melebihi berat badan ideal, sedangkan obesitas mempunyai arti berlebihan, dalam hal ini adalah penimbunan jaringan lemak yang berlebihan. ${ }^{4}$

Berdasarkan distribusi lemak pada tubuh, ada dua tipe obesitas, yaitu: ${ }^{5}$

- Tipe Android (tipe buah apel)

Tipe obesitas dengan distribusi lemak pada daerah perut.

- Tipe Gynoid (tipe buah peer)
- Tipe obesitas dengan distribusi lemak pada daerah pantat, pinggul, paha.

Menghitung Indeks Massa Tubuh (IMT) merupakan salah satu cara untuk mendiagnosa obesitas (Tabel 1). Rumus menghitung IMT adalah sebagai berikut :6

$$
I M T=\frac{\operatorname{Berat} \operatorname{Badan}(\mathrm{Kg})}{\operatorname{Ting} \operatorname{Badan}(\mathrm{m})} 2
$$

\section{Tabel 1. Klasifikasi Berat Badan Berdasarkan IMT untuk Asia ${ }^{7}$}

\begin{tabular}{cc}
\hline Nilai IMT & Klasifikasi \\
\hline$<18,5$ & underweight \\
$18,5-22,9$ & Normal \\
$23-24,9$ & Overweight \\
$25-29,9$ & Obese I \\
$>30$ & Obese II \\
\hline
\end{tabular}

Seorang perempuan mengalami menstruasi ketika sudah pubertas. Masa Pubertas di mulai sekitar usia 8-10 tahun dan berakhir sekitar usia 15-17 tahun (masa remaja). ${ }^{8}$ Dysmenorrhea adalah keluhan yang paling sering dirasakan dan merupakan salah satu dari beberapa gangguan menstruasi yang bisa mempengaruhi kualitas hidup dan produktivitas. Keluhan yang dirasakan adalah rasa nyeri yang diradsakan pada daerah panggul atau perut bagian bawah yang dapat menjalar sampai kepunggung dan sepanjang paha. ${ }^{9}$ Selain rasa nyeri keluhan lainnya dapat disertai sakit kepala, diare, mual muntah. ${ }^{9}$

Dysmenorrhea terbagi menjadi dua tipe, yaitu tipe dysmenorrhea primer dan dysmenorrhea sekunder. Dysmenorrhea primer diartikan sebagai keluhan berupa rasa nyeri kram perut bagian bawah saat mentruasi dan belum diketahui penyebabnya. Dysmenorrhea primer terjadi pada wanita dengan usia $<20$ tahun serta tidak ada hubungan dengan kelainan ginekologik, sedangkan pada dysmenorrhea sekunder sering terjadi pada wanita setelah usia 20 tahun dan adanya hubungan antara penyakit panggul atau system reproduksi. ${ }^{9}$

Beberapa faktor yang terkait dengan timbulnya dysmenorrhea, adalah: ${ }^{10}$

- Menarche pada usia dini

- Siklus menstruasi yang lama

- Aliran darah menstruasi terganggu

- Merokok

- Alkohol 
- Kafein

- Kurang olah raga

- Kurang asupan gizi

- Kelebihan berat badan dan obesitas

Berdasarkan data World Health Organization (WHO) tahun 2014, perempuan usia produktif berjumlah sekitar 1,2 milyar atau $18 \%$ dari jumlah penduduk di dunia, dan sekitar 45-93\% perempuan yang menstruasi menderita dysmenorrhea. ${ }^{11}$ Hasil data dari Kementrian Kesehatan (KEMENKES) tahun 2015 jumlah perempuan usia produktif di Indonesia sebanyak 43,5 juta atau sekitar $18 \%$ dari jumlah penduduk. ${ }^{12}$ Menurut hasil penelitian Pusat Informasi dan Konseling Kesehatan Reproduksi Remaja (PIK-KRR) di Indonesia tahun 2015 angka kejadian dysmenorrhea berkisar $45-95 \%$ di kalangan remaja dengan usia produktif, terdiri dari $72,84 \%$ dysmenorrhea primer dan 27,11\% dysmenorrhea sekunder. ${ }^{3}$ Pada penelitian Asmaulludin AK yang melibatkan siswi SMA dan sederajat tahun 2015 di Jakarta Barat, didapatkan angka kejadian dysmenorrhea sebesar $49,9 \% .^{13}$

Faktor pemberat yang dapat menyebabkan timbulnya dysmenorrhea, yaitu menstruasi pertama (menarche) pada usia $<12$ tahun, wanita yang belum pernah melahirkan anak (nulipara), banyaknya jumlah dari darah menstruasi atau menstruasi yang terjadi dalam jangka waktu yang cukup panjang, riwayat merokok, riwayat dysmenorrhea pada keluarga, serta kelebihan berat badan (obesitas). ${ }^{14}$

Berdasarkan uraian di atas, melihat banyaknya jumlah perempuan usia produktif di Indonesia dan meningkatnya angka kelebihan berat badan terutama pada perempuan usia produktif serta gangguan yang terjadi pada saat menstruasi (dysmenorrhea) perempuan usia produktif menjadi latar belakang saya untuk melalukan penelitian hubungan IMT dengan dysmenorrhea.

\section{Metodologi Penelitian}

Penelitian ini merupakan penelitian dengan metode observasional, dan menggunakan pendekatan potong lintang. Penelitian ini dilakukan di UKRIDA, Kebon Jeruk, Jakarta Barat, Indonesia, yang di mulai sejak bulan Juni hingga bulan Desember 2018, dengan 106 responden mahasiswi aktif Fakultas
Kedokteran dan Ilmu Kesehatan UKRIDA angkatan 2015.

\section{Alat dan Bahan Penelitian}

Alat yang digunakan pada penelitian ini adalah timbangan injak untuk mengukur berat badan, microtoise untuk mengukur tinggi badan, kalkulator, dan alat tulis. Sedangkan bahan yang diperlukan untuk penelitian ini adalah kuesioner yang akan diberikan kepada para responden sebelum dilakukan pemeriksaan pada penelitian ini.

\section{Cara Kerja}

Menyiapkan alat dan bahan penelitian berupa kuesioner, microtoise, timbangan injak, dan kalkulator, alat tulis, serta ruang untuk pemeriksaan di ruangan skill lab, lantai 3, gedung B kampus FKIK UKRIDA.

Pertama-tama peneliti melakukan seleksi singkat kepada mahasiswi-mahasiswi, yaitu dengan menanyakan apakah mahasiswi aktif berkuliah, dan menanyakan kesediaan calon responden untuk menjadi sampel penelitian yang akan dilakukan, dengan menjelaskan kepada calon responden tujuan penelitian dan pemeriksaan IMT yang akan dilakukan. Jika calon responden bersedia, maka selanjutnya responden diminta untuk membaca informed consent dan menandatanganinya sebagai bukti bahwa responden bersedia menjadi sampel penelitian. Setelah menandatangani informed consent, responden mengisi kuisoner yang sudah disediakan.

Setelah mengisi kuesioner, responden akan diperiksa tinggi badan dan berat badannya oleh peneliti menggunakan microtoise dan timbangan injak. Kemudian dicatat hasilnya pada kertas kuisoner responden masingmasing.

\section{Hasil Penelitian}

Hasil penelitian pada tabel 2 menunjukkan distribusi usia responden. Pada tabel 3, frekuensi terbanyak adalah responden dengan IMT normal, sedangkan responden yang memiliki masalah dengan IMT yang terbanyak adalah IMT overweight dan IMT obesitas I. 
Tabel 2. Distribusi Data menurut Umur dan Indeks Massa Tubuh Mahasiswi FKIK UKRIDA Angkatan 2015.

\begin{tabular}{lllll}
\hline & Mean & Max & Min & SD \\
\hline Usia & 21,4 & 26 & 19 & 1,08 \\
IMT & 22,3 & 34 & 15 & 3,86 \\
\hline
\end{tabular}

Tabel 3. Distribusi Data Menurut Indeks Massa Tubuh Mahasiswi FKIK UKRIDA Angkatan 2015.

\begin{tabular}{lcc}
\hline $\begin{array}{c}\text { Kelompok } \\
\text { Indeks Massa } \\
\text { Tubuh }\end{array}$ & Frekuensi & $\%$ \\
\hline Underweight $(<18,5)$ & 13 & 12,3 \\
Normal $(18,5-22,9)$ & 51 & 48,2 \\
Overweight $(23-24,9)$ & 17 & 16,0 \\
Obesitas I $(25-29,9)$ & 17 & 16,0 \\
Obesitas II $(>30)$ & 8 & 7,5 \\
\hline
\end{tabular}

Tabel 4 menunjukkan bahwa responden yang tidak nyeri adalah yang terbanyak, sedangkan di antara responden yang mengalami nyeri yang terbanyak adalah responden dengan nyeri sedang. Seperti yang ditampilkan dalam Tabel 5, responden yang bermasalah dengan IMT sebanyak 42 responden didapatkan 39 responden yang mengalami nyeri pada saat menstruasi. Setelah dilakukan uji statistik dengan rumus chi square didapatkan $\mathrm{p}$ value $=0,001 \quad(\mathrm{p}<0,05)$ menunjukkan adanya hubungan yang bermakna antara IMT dengan dysmenorrhea

Tabel 4. Distribusi Data Menurut Derajat Nyeri Mahasiswi FKIK UKRIDA Angkatan 2015.

\begin{tabular}{ccc}
\hline $\begin{array}{c}\text { Kelompok } \\
\text { Derajat Nyeri }\end{array}$ & Frekuensi & \% \\
\hline Tidak Nyeri & 43 & 40,6 \\
Nyeri Ringan & 16 & 15,1 \\
Nyeri Sedang & 24 & 22,6 \\
Nyeri Berat & 23 & 21,7 \\
\hline
\end{tabular}

Tabel 5. Hubungan Antara Indeks Massa Tubuh dengan Derajat Nyeri (Dysmennorhea).

\begin{tabular}{lcc}
\hline \multirow{2}{*}{$\begin{array}{l}\text { Indeks } \text { Mubuh } \\
\text { Tubsa }\end{array}$} & \multicolumn{2}{c}{ Derajat Nyeri } \\
\cline { 2 - 3 } & $\begin{array}{c}\text { Tidak } \\
\text { Nyeri }\end{array}$ & $\begin{array}{c}\text { Nyeri Ringan } \\
\text { /Sedang/Berat }\end{array}$ \\
\hline $\begin{array}{l}\text { Underweight } \\
(<18,5)\end{array}$ & 10 & 3 \\
$\begin{array}{l}\text { Normal }(18,5- \\
22,9)\end{array}$ & 30 & 21 \\
$\begin{array}{l}\text { Overweight/ } \\
\text { Obesitas I/ }\end{array}$ & 3 & 39 \\
Obesitas II (>23) & & \\
\hline
\end{tabular}

\section{Pembahasan}

Dysmenorea primer adalah tipe dysmenorea yang paling sering mengenai usia remaja dan dewasa muda. Pada penelitian yang dilakukan di negara India didapatkan prevalensi dismenorea primer yang cukup tinggi yaitu $74,9 \%$ dimana dysmenorea primer mencapai puncak pada usia 20 tahun dan menurun seiring dengan peningkatan usia. ${ }^{15}$ Penelitian yang dilakukan oleh Chia et.al. pada mahasiswi Universitas Hongkong didapatkan prevalensi dysmenorea primer yang tinggi yaitu sekitar $80 \% .{ }^{16}$ Penelitian tentang dysmenorea yang dilakukan oleh Dwi didapatkan kejadian dysmenorea pada responden FIK dan FKM UI mencapai $77,9 \%$ dengan mayoritas responden mengalami nyeri dismenorea derajat ringan. ${ }^{17}$ Pada penelitian ini didapatkan rata rata usia responden adalah 21 tahun dan angka kejadian sebesar $59,4 \%$ dengan mayoritas dengan derajat nyeri sedang.

Pada penelitian ini didapatkan hasil analisis antara IMT dengan dismenorea primer menunjukkan bahwa responden dengan IMT overweight lebih banyak mengalami dysmenorea. Hal ini sesuai dengan teori yang menyatakan bahwa IMT merupakan salah satu faktor risiko untuk terjadinya dysmenorea primer. Pada penelitian Singh et. al., menunjukkan bahwa kejadian dysmenorea lebih banyak dialami oleh responden dengan IMT overweight. ${ }^{18}$ Demikian pula penelitian yang dilakukan oleh dan Harlow et. al. kejadian dysmenorea lebih banyak dialami oleh responden dengan IMT overweight. ${ }^{19}$ 
Sedangkan Penelitian yang dilakukan oleh Omidvar dan Begum mendapatkan hasil bahwa responden yang memiliki IMT underweight lebih banyak mengalami dismenorea daripada responden dengan IMT overweight. ${ }^{20}$ demikian pula penelitian yang dilakukan oleh dan Khodakarami et. al. mendapatkan hasil bahwa responden yang memiliki IMT underweight lebih banyak mengalami dismenorea daripada responden dengan IMT overweight. ${ }^{21}$

Pada penelitian yang dilakukan di Indonesia, tentang faktor risiko dysmenorrhea yang dilakukan oleh Pande dan Purnawati didapatkan adanya hubungan antara indeks massa tubuh dengan dysmenorrhea. ${ }^{22}$ Hasil penelitian lainnya juga dilakukan oleh Widayanti pada 50 mahasiswi didapatkan 28 mahasiwi $(56 \%)$ dengan IMT overweight/obesitas mengalami keluhan dysmenorrhea. sedangkan 22 mahasiswi (44\%) lainnya dengan IMT normal tidak mengalami keluhan dysmenorrhea. ${ }^{23}$

Hasil yang berbeda didapatkan pada penelitian yang dilakukan oleh Lasmi, dkk dalam penelitiannya didapatkan responden dengan dysmenorrhea sedang hingga berat memiliki IMT underweight. ${ }^{24}$

\section{Simpulan}

Dari hasil data penelitian didapatkan adanya hubungan antara kelebihan berat badan dengan dysmenorrhea. Secara teoritis dysmenorrhea yang terjadi pada perempuan yang memiliki kelebihan berat badan disebabkan oleh estrogen yang meningkat, hal ini perlu adanya penelitian lebih lanjut apakah benar perempuan yang memiliki kelebihan berat badan memiliki kadar estrogen yang lebih tinggi dibandingkan pada perempuan yang memiliki berat badan yang normal.

\section{Daftar Pustaka}

1. Pratiwi H, Rodiani. Obesitas sebagai resiko pemberat dismenore pada remaja. Majority, 2015;4(9):96

2. Khotibuddin $\mathbf{M}$. Hubungan depresi dan perilaku makan terhadap berat badan lebih mahasiswa kedokteran. Mutiara Medika: 2017;17(1):42

3. Kementrian Kesehatan Republik Indonesia. Hasil Riset Kesehatan Dasar: Proporsi overweight dan obesitas pada usia
$>18$ tahun data tahun 20017-2018 dengan indikator pengukuran IMT. Jakarta: Depkes RI, 2018.

4. Rian Diana, Indah Yuliana, Ghaida Yasmin, Hardinsyah. Risk factors of overweight among indonesian women. jurnal gizi dan pangan. 2013;8(1):1-8

5. Bove CF, Sobal J. Body weight relationship in early marriage: weight relevance, weight comparisons, and weight talk. Appetite. 2011;(57): 729-42

6. Supariasa, I Made Nyoman, dkk. Penilaian Status Gizi. Jakarta: Penerbit Buku Kedokteran EGC. Ed 2. 2016;3(4):210-15

7. Supariasa. Indeks massa tubuh. Dalam: penilaian status gizi. Jakarta: EGC; 2012.

8. Zivanna A, Wihandani DM. Hubungan antara obesitas dengan prevalensi dismenorea primer pada mahasiswa Fakultas Kedokteran Universitas Udayana. Fakultas Kedoteran Udayana: E-Jurnal Medika.2017;6(5):2-3

9. Amimi S, Suarna M. Diagnosis and initial management of dysmenorrhea. American Family Physician. 2014;(3):343-9

10. Nurwana, Sabilu Y, Fachlevy AF. Analisis faktor yang berhubungan dengan kejadian dismenorea pada remaja putri di SMA Negeri 8 Kendari tahun 2016. Kendari, 2017;2(6):1-14

11. Alebtekin. Prevalence of chronic pelvic pain among women: An updated review. Pain Physician Journal. 2014;17:141-7

12. Kementrian Kesehatan Republik Indonesia. Infodatin pusat data dan informasi kementerian kesehatan Republik Indonesia: situasi kesehatan reproduksi remaja. Jakarta: Dinas Kesehatan Indonesia, 2015.

13. Asmaulludin AK. Kejadian dysmenorrhea berdasarkan karateristik orang dan waktu serta dampaknya pada remaja putri SMA dan sederajat di Jakarta Barat tahun 2015. Fakultas Kedokteran dan Ilmu Kesehatan Hidayatullah Jakart. 2016.

14. Beddu S, Mukarramah S, Lestaluhu V. Hubungan status gizi dan usia menarche dengan dismenorea primer pada remaja putri. The Southeast Asian J of Midwifery, 2015; 1(1):16-21

15. Shashikala K, Liya SR. Prevalence and risk factors for dysmenorrhoea among nursing student and its impact on their quality of life. Int $\mathbf{J}$ of Reprod Contraception, Obst and Gyn. 2018;7(7):2661-7 
16. Chia CF, Lai J, Cheung PK, Kwong L, Lau $\mathrm{F}$, Leung $\mathrm{K}$, et al. Dysmenorrhoea among Hong Kong University. Hong Kong Med J. 2013;19:222-8

17. Dwi P. "Hubungan antara karakteristik individu, aktivitas fisik dan konsumsi produk susu dengan dismenorea primer pada mahasiswi FIK dan FKM UI Depok tahun 2012" Skripsi. Depok: Universitas Indonesia, 2012.

18. Hong Ju, Mark Jones, Gita D. Mishra Singh A., Kiran D. A U-Shaped relationship between body mass index and dysmenorrhea: A longitudinal study. PLoS One. 2015;10(7)

19. Gurdip Kaur, Parmjit Kaur, Himani. A Study of the relation of BMI with dysmenorrhea in adolescents girls. Int. J. Curr. Res. Med. Sci. 2017;3(8):65-70

20. Omidvar S, Begum K. Characteristics and determinants of primary dysmenorrhea in young adults. Am Med Journal, 2012; 3(1):8-13

21. Khodakarami B, Masoumi B, Faradmal J, Nazari M, Saadati M, Sharifi, F. et al. The severity of dysmenorrhea and its relationship with body mass index among female adolescents in Hamadan, Iran. Journal of Midwifery and Reproductive Health. 2015;3(4):445-50

22. Pande NNUW, Purnawati S. Hubungan antara indeks massa tubuh dengan dysmenorrhea pada mahasiswi Fakultas Kedokteran Universitas Udayana. Skripsi. Bali: Fakultas Kedokteran Udayana, 2010.

23. Widayanti LP, Widawati PR. Correlation between body mass index and dysmenorrhea preclinical female students aged 16-24 at the Hang Tuah University Medical Faculty Surabaya. International Conference on Sustainable Health Promotion, 2018: 66-70.

24. Lasmi KKH, Wibawa A, Mullarta IM. Hubungan antara indeks massa tubuh (IMT) kategori underweight dengan tingkat nyeri dysmenorrhea primer remaja putri sekolah menengah pertama. Jakarta: Majalah Ilmiah Fisioterapi Indonesia. 2017;6(3):27 